\title{
Effect of Traditional Methods of De-bittering on the Proximate and Vitamin Contents of Fresh and Squeezed-Washed Bitter Leaf
}

\author{
Agomuo Jude Kelechi ${ }^{1, ~}$, Alaka Ignatius Chukwuemeka ${ }^{2}$, Akajiaku Linda Oluchi ${ }^{3}$, Taiwo Mayomi ${ }^{1}$ \\ ${ }^{1}$ Department of Food Science and Technology, Federal University Dutsin-ma, Katsina State, Nigeria \\ ${ }^{2}$ Department of Food Science and Technology, Ebonyi State University, Ebonyi State, Nigeria \\ ${ }^{3}$ Department of Food Science and Technology, Federal University of Technology Owerri, Owerri, Imo State, Nigeria
}

Email address:

jagomuo@fudutsinma.edu.ng (A. J. Kelechi), lindaoakajiaku@gmail.com (A. L. Oluchi)

\section{To cite this article:}

Agomuo Jude Kelechi, Alaka Ignatius Chukwuemeka, Akajiaku Linda Oluchi, Taiwo Mayomi. Effect of Traditional Methods of De-bittering on the Proximate and Vitamin Contents of Fresh and Squeezed-Washed Bitter Leaf. International Journal of Nutrition and Food Sciences. Vol. 4, No. 1, 2015, pp. 103-110. doi: 10.11648/j.ijnfs.20150401.24

\begin{abstract}
Bitter leaf is a leafy vegetable that is widely consumed and cherished in South-Eastern Nigeria. The effect of traditional methods of de-bittering of bitter leaf (Vernonia amygdalina) on the proximate and vitamin contents was studied using potash, palm oil, and salt and boiling process in squeeze-washing at 3 pre-processing methods of squeeze-wash and periods of 3 to 8 minutes. The percentage retention and losses of nutrients increased simultaneously during squeeze-washing. The sample squeezed-washed with palm oil had nutrient retention ranging between 55 to $100 \%$ of moisture, ash, crude fibre, fat, vitamin A and vitamin $\mathrm{C}$ than other squeeze-washed samples. This could be due to the rigidity of the cells of the sample squeezed-washed with palm oil which did not allow much nutrient to leach into the squeezed leaf water; whereas, the loss of nutrient was practically of the same magnitude $(27.3$ to $80.5 \%)$ in all other samples. The loss of nutrients was observed to be influenced directly by the cause-and-effect of disintegration changes which usually leads to softening due to the severity of the squeeze-washing on the bitter leaf instead of cellular composition or level of nutrient initially present. Palm oil should be used in the squeeze-washing of bitter leaf for better nutrient retention.
\end{abstract}

Keywords: Bitter Leaf, Palm Oil, Potash, Salt, Squeeze-Washing

\section{Introduction}

Leafy vegetables constitute an indispensible constituent of human diets in Africa generally and in Nigeria in particular (Okudu, 2008). They could be eaten either raw or cooked and contain both essential and toxic elements with wide range of concentrations (Kola, 1999). Leafy vegetables have high water content and an abundance of cellulose though not digestible, serves a useful purpose in the intestine as roughages, thus, promoting normal elimination of wastage (Adeboye and Babajide, 2007).

In Nigeria as in other tropical countries of Africa, where the daily diet is dominated by starchy staple foods, leafy vegetables are the cheapest and most readily available sources of important vitamins and minerals with some of them containing protein (Okafor, 1983). Leafy vegetables as a group are low in fat, energy and appreciably high in ascoibic acid (Ejohet et al., 2007).
Bitter leaf (Vernonia amygdalina) is a perennial plant belonging to the compositae family (Igile et al., 1995,). Their leaves are dark green coloured with a characteristic odour and a bitter taste (Aina and Uko, 1990). The plant is grown in the garden around the homestead in Nigeria for a quick supply (Ajebesone and Aina, 2004). Unlike any other leafy vegetable, bitter leaf is cherished in some Igbo Speaking area of South-Eastern Nigeria because of the distinctive flavour it imparts to any food of which it is a component (Morah and Obiegbuna, 2002). According to Latham (1997), the consumption of bitter leaf and how it is prepared in most localities is greatly influenced by social factors and cultural practices of the people. The leaves are eaten after crushing and squeeze washing them thoroughly to remove the bitterness (Mayhew and Penny, 1998). Processing most times if not always, modifies the nutrient composition especially vegetables which easily lose their water soluble or heat labile nutrient. The process of squeeze- washing with palm oil, 
potash and salt has not been studied and comparing the normal squeezed - washed leaves with the ones squeezewashed with palm oil, potash and salt will show clearly which method optimally preserve the overall nutrient composition.

This work therefore investigates the proximate and vitamin contents of fresh and squeeze-washed bitter leaf as affected by traditional methods of de-bittering.

\section{Materials and Methods}

The fresh bitter leaves were bought randomly from three different sellers in a local market in Umuahia, Abia State. This market was chosen because of its peculiarity with the processing and selling of bitter leaf.

\section{Sample Preparation}

The fresh bitter leaves were sorted, de-stalked and rinsed in water to remove dust and dirt, and were left to drain. They were then divided into six parts. The six parts were individually subjected to different local processing methods.

The first de-bittering method was normal squeeze-washing. The bitter leaves were squeeze-washed by breaking, squeezing and rinsing of the sample to remove bitterness. The process of squeezing and rinsing was done in 3 preprocessing rounds; $8 \mathrm{mins}$ each, for the first and second intervals while the third interval is for 5 mins making a total of 21 mins. Rinsing was done when enough foam was formed that prevented successful squeeze- washing.

The second de-bittering method was squeeze-washing and boiling. The sample was squeeze-washed using the same procedure as described in the first process but not as intense as was done to the sample. In this process, squeeze- washing was mild as it was for only $14 \mathrm{mins}$ ( 3 pre-processing rounds of 8mins, 3mins.) And this made it possible for the bitter leave samples to retain high level of bitterness. The mildly squeeze- washed bitter leaves were then introduced into boiling water in an iron pot to boil for 2 mins at $115^{\circ} \mathrm{C}$.

The third treatment involved the addition of $5 \mathrm{~g}$ of salt while squeeze-washing the bitter leaf. The process lasted for 11 mins after 3 rounds of squeeze-washing.

The fourth treatment was squeeze washing with the addition of $5 \mathrm{~g}$ of ground potash. Also this process lasted for 11 mins at 3 rounds of squeeze - wash. The fifth treatment involved the addition of $5 \mathrm{ml}$ of Palm oil in order to retain the fibrous tissue of the leaves. The unprocessed sample served as the control. Before any of these samples was analyzed, it was reduced in size by pounding it in a mortar with pestles.

\section{Proximate Analysis}

The proximate compositions of the vegetables were determined on the edible portions of bitter leaf, according to the association of official analytical chemist (A.O.A.C., 2005). All analysis was carried out in triplicates.

\section{Determination of Vitamin Contents}

Vitamin A: In vitamin A determination, the method described by Okwu (2004) was employed. A measured mass $(5 \mathrm{~kg})$ of each prepared sample was dispensed in $30 \mathrm{ml}$ absolute alcohol. Three millilitres $(3 \mathrm{ml})$ of $50 \% \mathrm{KOH}$ solution was added to it and boiled under reflux for 30 minutes. After rapidly cooling in running water, $30 \mathrm{ml}$ of distilled was added to it and the mixture was transferred to separation funnel. three portions of $50 \mathrm{ml}$ of either was used to wash the mixture, thus extracting the vitamin A the lower aqueous layer was discarded, while the vitamin A extract was washed with $50 \mathrm{ml}$ distilled water. Care was taken to avoid formation of emulsion. The extract was then evaporated to dryness and dissolved in $10 \mathrm{ml}$ of isopropyl alcohol and its absorbance of vitamin A was measured at $325 \mathrm{~mm}$ wavelength. Meanwhile, the standard vitamin A was dissolve in isopropyl alcohol and its absorbance was measured at $325 \mathrm{~mm}$. the vitamin A content was calculated using the relationship below:

$$
\text { Vitamin A (iu/100g) }=\frac{100}{W} \times \frac{A U}{A S} \times C
$$

$\mathrm{AU}=$ absorbance of sample, $\mathrm{W}=$ weigh of sample

$\mathrm{AS}=$ Absorbance of standard, $\mathrm{C}=$ concentration of vitamin

Vitamin $\mathrm{B}_{1}$ (thiamine): Thiamine content of the samples was determined using the dischromate colourimetric method describe by Okwu and $\mathrm{Ndu}$ (2006). A weighed portion of each part of a sample $(5 \mathrm{~g})$ was extracted by homogenate was filtered to obtain the extract. An aliquot of the extract $(10 \mathrm{ml})$ was treated with $1 \mathrm{ml}$ of moral potassium dichromate solution. Standard thiamine solution was prepared and treated the same way as the sample. A reagent blank consisting of the extracting solution alone was also treated the same way. The reagent blank was used to set to the instrument at zero. The absorbance of the standard solution and test extracts were read in a jenway model spectrophotometer at a wavelength of $360 \mathrm{~mm}$.

The thiamine content was calculated as show below:

$$
\text { Thiamine }(\mathrm{mg} / 100 \mathrm{~g})=\frac{100}{W} \times \frac{a u}{a s} \times C \times \frac{v f}{v a}
$$

Where $\mathrm{W}=$ weigh of sample analyzed

$\mathrm{Au}=$ absorbance of sample

Us $=$ absorbance of the standards

$\mathrm{C}=$ concentration of the standard

$\mathrm{Vf}=$ total volume for extract

$\mathrm{Va}=$ volume of extract analyzed

Vitamin $\mathrm{B}_{2}$ (riboflavin): A measured weight (50g) of the sample was treated with $100 \mathrm{ml}$ of $50 \%$ ethanol solution and shaken for one hour for extraction. This was filterer into a $100 \mathrm{ml}$ flask. A measured volume $(10 \mathrm{ml})$ of the extract was pipetted into a $50 \mathrm{ml}$ volumetric flask. To this, $10 \mathrm{mls}$ of $5 \%$ potassium permanganate and $10 \mathrm{mls}$ of $30 \% \mathrm{H}_{2} \mathrm{O}_{2}$ were added and allowed to stand over a hot water bath for about 30 mins. Afterword $2 \mathrm{mls}$ for $40 \%$ sodium sulphate solution 
was added and a yellowish pale colour was formed. This was made up to $50 \mathrm{ml}$ mark and the absorbance measured at $510 \mathrm{~nm}$ wavelength in a jenway spectrophotometer.

Vitamin $\mathrm{B}_{3}$ (Niacin): The method of the association of chemists described by Okwu (2004) was employed. Five grams $(5 \mathrm{~g})$ of the sample was treated with $50 \mathrm{ml}$ of $1 \mathrm{~N}$ sulphuric acid and shaken for 30mins. Three drops of ammonia solution was added to the sample and filtered. A measured volume $(10 \mathrm{ml})$ of the filtrate was pipetted into a $50 \mathrm{ml}$ volumetric flask and $5 \mathrm{mls}$ of potassium cyanide was added. This was acidified with $5 \mathrm{mls}$ of $0.02 \mathrm{~N}$ sulphuric acid and its absorbance was measured in the Jenway model spectrophotometer at $47 \mathrm{~nm}$ wavelength.

Ascorbic Acid (Vitamin C): Vitamin C was determined using the method for vitamin assay (inter-science publishers, 2006). This method is based on the reduction of the dye $(2,6$ dichlorophenolindophenenol) by an acid solution of ascorbic acid. The capacity of an extract of the sample to reduce a standard solution of the dye, as determined by titration is directly proportional to the ascorbic acid content. Two hundred grams $(200 \mathrm{~g})$ of each sample was blended with $6 \%$ $\mathrm{HPO}_{3}$ to yield homogenous slurry. $10 \mathrm{~g}$ of each sample slurry was weighed into a $100 \mathrm{ml}$ volumetric flask and diluted to $100 \mathrm{ml}$ with $3 \%$ meta phosphoric acid solution $(0.0033 \mathrm{M}$ EDTA). The diluted samples were filtered, pipetted into a small flask and titrated immediately with a standardized solution of 2.6 dichlorophenol-in dephenol to a faint pink end point which persisted for about $15 \mathrm{sec}$. The ascorbic acid content of the fruit was calculated from the relationship below.

$$
\frac{V}{W} \times T \times 100=\mathrm{mg} \text { ascorbic acid per } 100 \mathrm{~g} \text { sample. }
$$

Where, $\mathrm{V}=\mathrm{ml}$ dye used for titration of aliquot of diluted sample.

$\mathrm{T}=$ ascorbic acid equivalent of dye solution expressed as $\mathrm{mg}$ per $\mathrm{ml}$ of dye

$\mathrm{W}=$ gram of sample in aliquot titrated.

\section{Statistical Analysis}

The proximate and vitamin compositions were determined by different methods. The data obtained were subjected to analysis of variance (ANOVA) to determine any significant difference at 5\% level $(\mathrm{p}<0.05)$ using Wahua (1999) method and was reported as means of three replicate.

\section{Result and Discussions}

The data obtained as shown in table 1 , reveals that, the moisture content of the bitter leaf samples which ranged from $80.3 \%$ to $92.1 \%$ was within range of moisture content in fresh green leafy vegetables, that ranged from $72 \%$ in cassava leaves to $92.93 \%$ in indian spinach and water leaf. It has also been reported that the amount of moisture content in individual samples of green leafy vegetables depends on several factors which includes age, freshness and agronomical practices prevailing during cultivation (Oguntona, 1998; Uwaegbute, 1989).

Ejoh et al. (2007a) stated that the amount of moisture content in a food affects the packaging, keeping quality, nutrient provided and the types and rate of microbial spoilage that occur. Hence, vegetables such as, this should be consumed fresh after harvest or preserved by freezing or by drying in order to increase the shelf-life, prevent microbial growth and enzymatic activities in the vegetables (Enwere, 1998).

The ash contents of bitter leaf obtained in this study (2.27$3.24 \%$ ) is similar to the value reported by Saidu and Jideobi (2001), Ajayi et al (2006) in pump kin (2.01\%) and waterleaf $(2.50 \%)$. The results also compare to $3.72 \%$ for "Ukazi" as reported by Okafor (1979) but lower than that of conventional and popular Amaranthus sp and moringa oleifeira vegetables (Adepoju et al., 2006). The ash content reflected the amount of minerals in specific bitter leaf samples. Bitter leaf squeeze - washed with potash had the highest ash content $(3.24 \%)$ which was probably responsible for its high mineral content.

Leafy vegetables are known to be poor sources of lipids, thus the low fat content $(0.99-2.34 \%)$ of the bitter leaf samples was in agreement with reports that vegetables as a group are low in fat content (Ejohet al., 1996; Ifon, 1980). However, the values obtained were comparable with that of Baobab (1.68\%) and Okra leaves (0.97\%) (Ihekoronye and Ngoddy, 1985). According to Okafor (1995), Lewu et al. (2009) and Gupta et al. (2005), the fat content of Colosia argenta, Gnetum africanum, Colocasia esculenta L. were 0.7, 1.2 and $1.85 \%$, respectively, which are in line with the results obtained in this study. Fats and oil are recognized as essential nutrients in human and animal diets. They provided concentrated energy, supply essential fatty acids and are carriers of the fat soluble vitamins A, D, E and k. More so, they serve to make the food more palatable, giving a sense of fullness following a meal. However, the American Dietetic Association suggested that diets should contain less than $30 \%$ fat (Smith, 1983). Therefore, increasing the consumption of these vegetable would naturally lower the percentage of total fat intake. More importantly, no cholesterol is found in fruits and vegetables (Lymido et al., 1991).

The fibre content $(9.3-20.12 \%)$ of the bitter leaf samples were within the range when compared with Gnetum africanum (12.50\%), pterocarpies soyauxii (14.2\%), amaranthus hybridus (8.61\%) and colocasia esculenta L. (26.4\%)vegetables (Chimaand Iygor 2007; Akubugwo et al., 2007; Lewu et al., 2009). It is significant in human nutrition as the therapeutic effects of fibre in the prevention of heart disease, colon cancer and diabetes and its role in the treatment of digestive disorders (diverticulosis and constipation) are generally recognized as reported by Lund (1982) and Kelsay (1985).

Overall, fresh green leafy vegetables are low in protein content (Ifon and Bashir, 1987). However, the protein content of the bitter leaf samples was high (3.216-6.04\%) when compared to mean values of crude protein of $4.2 \%$ for 
seventeen of such vegetables as reported by Aletor and Adeogum (1995). This can be attributed to the maturity stage of the vegetables. Thus, adequate consumption of these vegetables and proteins from other sources will help in supplying amino acids for growth, replacement of damaged tissues, and formation of body enzymes, hormones and antibodies.

The carbohydrate values obtained $(6.02 \%-10.05 \%)$ were high and could compare favourably with that of Gentum africanum and Pterocarpies soyauxii vegetables (Chima and Iygor, 2007). The result also agrees with those reported for Colocasia esculenta, which was between 12-15\% according to Lewu et al. (2009). Carbohydrates are needed majorly for providing energy. Though green leafy vegetables are not good dietary sources of energy, yet the body uses the calories contained in all foods (including vegetables) to produce energy and warmth to the system. Excess calories are stored in the adipose tissue for use at the time when sufficient calories would not be available.

The low gross energy value of the bitter leaf samples $(1.02 \%-2.11 \%)$ could have resulted from their low crude protein, lipid and carbohydrate contents. This is a reflection on the low dry matter content of many of these leaves (Oguntona, 1998). These contribute to the energy needs of the body for growth, development and metabolic processes.

Vitamin A is present in plant food as B- carotene and in animal source as retinol (Lean, 2006) and is found as a constituent of the red cells in the retina, where it helps proper vision in dim light.

Table 2 shows that the vitamin A content of bitter leaf obtained in this study is similar to the value reported by Atangwho et al. (2009). International unit is used to express the potency of drugs or particular nutrients. One international unit (IU) is equivalent to $0.6 \mu \mathrm{g}$ (Micro gram) of $\mathrm{B}$-carotene. One microgram is equivalent to 103 milligram. Some literature (Lean, 2006; Nkafamiya et al., 2010) reported the vitamin A contents of some vegetables in micrograms. The equivalent value of $356.841 \mathrm{U}$ in micrograms is 214 .ug. The vitamin A content of the bitter leaf used in this study is $214.104 u g$. This value was quite high when compared to the value of some vegetables reported by Lean (2006). It is higher than the vitamin A values reported for B. cosatum and M. Oleifera by Nkafamiya et al. (2010). Lean (2006) reported a reference nutrient intake of $700 \mathrm{ug}$ of carotene $\backslash$ day for adult male and 600ug of carotene /day for adult females; bitter leaf with a vitamin A content of $214.104 \mathrm{ug} / 100 \mathrm{~g}$ could serve as a good source of this nutrient and consequently aid in prevention of impaired vision associated with vitamin $\mathrm{A}$ deficiency.

B -carotene (Vitamin A precursor) is found to be present in the small amount of fat present in green leafy vegetables and is the squeeze- washing leaches very little or no vitamin A into the washing water. This is in conformity with the report of Hildreth (1971) that vitamin A being a fat soluble vitamin is less readily leached out into the washing water.

The vitamin A content of the sample subjected to squeeze -washing and boiling was significantly lower $(\mathrm{p}<0.0 .5)$ than that of the sample subjected to only squeeze-washing. Lean (2006) had earlier reported that vitamin a is susceptible to heat. This report also agrees with the work of Uwaegbute et al. (2010) that heating of vegetables significantly reduced their vitamin A content. It is also established that bleaching of vegetable oils by heating decolourize the oil, greatly destroys the $\mathrm{B}$ - carotene content of the vegetable oil.

There is no significant difference between samples squeeze- washed with palm oil and the normal squeezewashed one. This is due to the fact that palm oil contains vit A. (Lean 2006).

Vitamins C are highly soluble in water, susceptible to heat, sensitive to light and oxidation (Hildeth, 1971; Julie, 2003; Ruttledge, 1991; Lean, 2006).

The value of the ascorbic acid content of the Vernonia amygdalina used in this work compared very well with that obtained by Atangwho et al. (2009) and Ejoh et al. (2005) for $V$. amygdalina and other Vernonia species. This value is high enough to meet the reference intake (RNI) of $40 \mathrm{mg}$ of vitamin $\mathrm{C}$ /day for males and females (Lean, 2006) vitamin C is referred to as anti-scorbutic vitamin (anti-scurvy acid). It assists in the proper formation of collagen, a fibrous structural protein found in joints. It is needed for healthy gums, teeth and a clear skins, vitality and endurance (Hildreth, 1971; Lean, 2006). Its deficiency in diets leads to the disease, scurvy (Said and Mohammed, 2006). The values obtained for squeeze -washed bitter leaf samples used in this work were significantly lower $(p>0.05)$ than the fresh sample because ascorbic acid is very soluble in water. The operation of squeeze - washing to remove bitterness, damages the tissues of the leafy vegetable, rupturing the cells and exposing more areas of the sample to washing water.

Vitamin C like other nutrients is contained inside the cytoplasm of the cells. Thus, for any dissolution of ascorbic (vitamin C) from the cell into the washing water, there must be movement through the cell wall down a concentration gradient. For leafy vegetables and other food materials containing vitamin $\mathrm{C}$, ordinary soaking or washing in water without rupturing of the cells by shredding, dicing or crushing results to lower vitamin losses than when the cells are ruptured. Ejoh et al. (2005) reported significant reductions in the vitamin $\mathrm{C}$ contents of $V$. amygdalina and $V$. calvoana var bitter when squeeze- washed.

The bitter leaf sample subjected to squeeze - washing and boiling was significantly lower $(p>0.05)$ in ascorbic acid contents than that of the sample subjected to only squeezewashing. The combined effect of squeeze- washing and boiling leached out more ascorbic acid. This is because solubility increases with increase in solubility of solvent (water). The lower value of vitamin $\mathrm{C}$ in this sample was due to the leaching of vitamin into the washing water and the subsequent dissolution of the vitamin in the boiling water. The heating also contributed to higher level of losses in vitamin C. Hildreth (1971) had earlier reported that the mechanism of degradation of ascorbic acid in three leafy vegetables studied (C.olitorius, A. hybrius, T. occidentalis ) appears to be dependent on thermally induced energy 
intensity on physico-chemical changes and the ability to sustain cell stability and turgor pressure rather than the composition of the vegetable. They also reported that losses as high as 48 to $74 \%$ of ascorbic acid would occur when vegetables are blanched which is also in line with the result obtained.

Squeeze- washing increases the surface area of the leafy vegetable to the water thereby increasing leaching losses. If vegetables are put in cold water which is heated to boil, the dissolved oxygen in the water will in the presence of oxidases (oxidizing enzymes), destroy a substantial amount of the ascorbic present. The oxidases are most active at about $60-80^{\circ} \mathrm{C}$ and above these temperatures are quickly inactivated (Lean, 2006). The same reason is in the case of squeeze -washing and boiling with salt and potash. Hildreth (1971) opined that high alkalinity destroys Vit C. therefore; high alkaline nature of the squeeze water affected the Vit. C content of the sample squeeze- washed with salt and potash.

Thiamine is a water soluble vitamin and controls the liberation of energy from carbohydrate foods by way of complete oxidation of glucose in the system (Julie, 2003). Absence of vitamin B1 in diet leads to a loss of appetite, fatigue, indigestion and constipation, with prolonged deficiency leading to beriberi (Hildreth, 1971; Lean, 2006). The thiamine content of bitter leaf in this study compares very well with value reported by Lean (2006) for some vegetable. The value of the thiamine content $(0.19+0.005 \mathrm{mg} / 100 \mathrm{~g})$ is lower than values reported by Akubugwo et al. (2007) and Nkafaiya et al. (2010) for $A$. hybridus and M. oleifera, respectively. Lean (2006) stated that the Reference Nutritional Intake (RNI) of thiamine is dependent on the amount of carbohydrate intake. He reported a reference (RNI) of $0.4 \mathrm{mg}$ of thiamine $/ 1000 \mathrm{kcal}$. Considering the amount of carbohydrate consumed in Nigeria, the thiamine content of the bitter leaf in this study is not enough to meet the RNI.

Thiamine content of the bitter leaf in this study was affected by different de-bittering methods. The bitter leaf sample subjected to squeeze-washing and boiling had the lowest thiamine content. Thiamine is very soluble in water and as much as 50 percent may be lost when vegetables are boiled (Lean, 2006). The significant loss of thiamine for squeeze -washed bitter leaf as reported in this study also agreed with that reported by Lean (2006). Squeeze -washing operation increasing the surface area, thereby making more of vitamin to come in contact with the boiling water.

Thiamine is destroyed by high temperature of boiling water (Hildreth, 1971). The susceptibility of thiamine to heat was also reported by Lean (2006) as he opined that thiamine decomposes on heating. Nkafamiya et al. (2010) had earlier reported that thiamine (vitamin B1) contents of leafy vegetables are reduced drastically after blanching operation. Latunde- Dada (1990) had also reported that the processing operation of squeeze- washing ruptures the cells of leafy vegetables and paves way for leaching of thiamine into the washing and rinsing water.

The riboflavin content of the unprocessed raw bitter leaf,
$0.22+0.0 \mathrm{mg} / 100 \mathrm{~g}$ is lower than values reported by Akubugwo et al. (2007) and Nkafamiya et al. (2010) for $A$. hybridus, M. Oleifera and B. cosatum. This value is however, higher than those reported by Lean (2006) for cabbage and potatoes. Lean (2006) stated that the reference nutrient intake (RNI) of riboflavin is dependent on basal metabolic rate. He gave the RNI of riboflavin as $1.3 \mathrm{mg}$ /day for adult males, $1.1 \mathrm{mg} /$ day for adult females.

The riboflavin content of the squeeze-washed bitter leaf is lower than the RNI, although, it could perform well as a fair source of the vitamin if the quantity of the bitter leaf consumed per day is increased. The importance of riboflavin is in the oxidation of carbohydrate for energy release as well as in the avoidance of inflammation of the mouth, tongue and cornea of the eye (Julie, 2003). Riboflavin is only slightly soluble in water with minimal losses occurring during boiling of foods containing the vitamin (Lean, 2006). The squeeze- washed bitter leaf sample had a riboflavin content that was significantly lower than that in the fresh sample $(p<0.05)$. Like other vitamins which are soluble, the process of squeezewashing ruptures the cells of the leafy vegetable, leading to increased leaching losses of vitamin. This finding is in agreement with the report of Oguntona (1998) that squeezewashing leaches some riboflavin into the washing water.

There were no significant differences $(p>0.05)$ in the riboflavin contents of bitter leaf subjected to squeezewashing process and that of squeeze-washed and boiled $(p>0.05)$ due to the heat stability of vitamin. Studies by Eunok et al. (2005) showed that heating barely affects the riboflavin in foods. High amounts of riboflavin in roasted pork were retained after a heating process that significantly destroyed most other vitamins (Lassen et al., 2002). Lean (2006) opined that little or no loss of riboflavin occurs during canning of food.

Niacin, a moderately water soluble vitamin is important in diets as anti-pellagra vitamin and in releasing energy from carbohydrate foods (Lean, 2006). It is fairly present in vegetable foods. The amino acid tryptophan in milk is usually converted by the body into the vitamin. The niacin content of bitter leaf reported in this study is $0.88+0.289 \mathrm{mg} / 100 \mathrm{~g}$ and compares well with the values reported by Nkafamiya at al. (2010). The niacin content of the studied bitter leaf is lower than the niacin content of potato $(1.5 \mathrm{mg} / 100 \mathrm{~g})$, which is regarded as a good source of the vitamin (Lean, 2006; Hildreth, 1971). Lean (2006) also stated that the RNI of niacin for good health is related to the energy content of the diet and the amount of tryptophan also present. He gave the RNI of niacin for all ages and both sexes (except lactating women) as $6.6 \mathrm{mg}$ niacin $/ 1000 \mathrm{kcal}$.

Squeeze -washing significantly reduced $(p<0.05)$ the niacin content of bitter leaf. This is in agreement with the report of Lean (2006) that some amounts of the vitamin are lost to wash water. Niacin is a water soluble vitamin like other B-vitamin and is easily absorbed in water. The result of this study showed that the processing method had no significant difference $(p>0.05)$ on the niacin content of leafy vegetable. Niacin is the most stable vitamin to the processing 
methods given to $V$. amygdalina in this study. This agrees vitamin among the B- vitamins. with report of Lean (2006) that niacin is the most stable

Table 1. Proximate composition of different samples of Vernonia Amydalina on wet basis ( $g / 100 g)$.

\begin{tabular}{lllllll}
\hline Parameter & Unpro-cessed & $\begin{array}{l}\text { Normal squeeze } \\
\text { washed }\end{array}$ & $\begin{array}{l}\text { Squeezed washed } \\
\text { and boiled }\end{array}$ & $\begin{array}{l}\text { Squeezed } \\
\text { washed with salt }\end{array}$ & $\begin{array}{l}\text { Squeezed washed } \\
\text { with potash }\end{array}$ & $\begin{array}{l}\text { Squeezed washed with } \\
\text { palm oil }\end{array}$ \\
\hline Dry matter & $9.2 \pm 0.16^{\mathrm{a}}$ & $8.7 \pm 0.20^{\mathrm{b}}$ & $7.8 \pm 0.11^{\mathrm{c}}$ & $7.9 \pm 0.10^{\mathrm{c}}$ & $7.3 \pm 0.18^{\mathrm{d}}$ & $9.0 \pm 0.01^{\mathrm{a}}$ \\
Moisture & $90.0 \pm 0.16^{\mathrm{a}}$ & $87 . \pm 0.12^{\mathrm{b}}$ & $86.4 \pm 0.02^{\mathrm{b}}$ & $81.9 \pm 0.10^{\mathrm{c}}$ & $80.3 \pm 0.18^{\mathrm{c}}$ & $92.1 \pm 0.02^{\mathrm{a}}$ \\
Ash & $2.39 \pm 0.19^{\mathrm{c}}$ & $3.03 \pm 0.02^{\mathrm{ab}}$ & $2.90 \pm 0.18^{\mathrm{b}}$ & $2.27 \pm 0.17^{\mathrm{c}}$ & $3.24 \pm 0.04^{\mathrm{a}}$ & $3.04 \pm 0.16^{\mathrm{b}}$ \\
Crude fibre & $1.55 \pm 0.30^{\mathrm{d}}$ & $1.60 \pm 0.30^{\mathrm{c}}$ & $1.44 \pm 0.20^{\mathrm{c}}$ & $1.39 \pm 0.02^{\mathrm{f}}$ & $2.67 \pm 0.02^{\mathrm{a}}$ & $2.49 \pm 0.27^{\mathrm{b}}$ \\
Crude protein & $1.01 \pm 0.01^{\mathrm{a}}$ & $0.95 \pm 0.01^{\mathrm{b}}$ & $0.55 \pm 0.29^{\mathrm{c}}$ & $0.67 \pm 0.30^{\mathrm{c}}$ & $0.43 \pm 0.02^{\mathrm{d}}$ & $0.69 \pm 0.20^{\mathrm{c}}$ \\
Carbohydrate & $1.87 \pm 0.12^{\mathrm{b}}$ & $1.92 \pm 0.11^{\mathrm{b}}$ & $1.88 \pm 0.33^{\mathrm{b}}$ & $2.30 \pm 0.18^{\mathrm{a}}$ & $1.33 \pm 0.18^{\mathrm{c}}$ & $1.93 \pm 0.13^{\mathrm{b}}$ \\
Fat & $2.34 \pm 0.18^{\mathrm{a}}$ & $1.57 \pm 0.30^{\mathrm{c}}$ & $1.47 \pm 0.19^{\mathrm{d}}$ & $0.99 \pm 0.20^{\mathrm{c}}$ & $1.15 \pm 0.16^{\mathrm{e}}$ & $1.79 \pm 0.03^{\mathrm{b}}$ \\
Energy $(\mathrm{kcal} / \mathrm{g})$ & $2.01 \pm 0.02^{\mathrm{a}}$ & $1.02 \pm 0.08^{\mathrm{c}}$ & $1.86 \pm 0.30^{\mathrm{b}}$ & $2.06 \pm 0.03^{\mathrm{a}}$ & $2.11 \pm 0.99^{\mathrm{a}}$ & $1.82 \pm 0.02^{\mathrm{b}}$ \\
\hline
\end{tabular}

Values are means and standard deviations of three replicates; means with the same superscript are not significantly different $(\mathrm{p}<0.05)$

Table 2. Vitamin contents of different samples of Vernonia amydalina on wet basis.

\begin{tabular}{|c|c|c|c|c|c|}
\hline Samples & $\begin{array}{l}\text { Vitamin A } \\
\text { (iu/100g) }\end{array}$ & $\begin{array}{l}\text { Vitamin C } \\
(\mathrm{mg} / \mathbf{1 0 0 g})\end{array}$ & $\begin{array}{l}\text { Vitamin B1 } \\
\text { (mg/100g) }\end{array}$ & $\begin{array}{l}\text { Vitamin B2 } \\
\text { (mg/100g) }\end{array}$ & $\begin{array}{l}\text { Vitamin B3 } \\
(\mathrm{mg} / 100 \mathrm{~g})\end{array}$ \\
\hline Unprocessed & $357.18 \pm 0.05^{\mathrm{a}}$ & $163.20 \pm 0.01^{\mathrm{a}}$ & $0.19 \pm 0.008^{\mathrm{a}}$ & $0.22 \pm 0.02^{\mathrm{a}}$ & $0.88 \pm 0.02^{\mathrm{a}}$ \\
\hline Normal squeeze washed & $355.92 \pm 0.10^{\mathrm{a}}$ & $88.41 \pm 0.69^{b}$ & $0.099 \pm 0.02^{\mathrm{b}}$ & $0.16 \pm 0.01^{\mathrm{b}}$ & $0.53 \pm 0.00^{\mathrm{b}}$ \\
\hline Squeeze washed and boiled & $246.91 \pm 0.02^{\mathrm{b}}$ & $49.28 \pm 0.03^{c}$ & $0.077 \pm 0.01^{\mathrm{d}}$ & $0.15 \pm 0.02^{b}$ & $0.51 \pm 0.01^{b}$ \\
\hline Squeeze washed with salt & $196.80 \pm 0.03^{\mathrm{d}}$ & $42.10 \pm 0.02^{d}$ & $0.080 \pm 0.01^{\mathrm{d}}$ & $0.148 \pm 0.08^{b}$ & $0.50 \pm 0.01^{b}$ \\
\hline Squeeze washed with potash & $194.99 \pm 0.01^{\mathrm{d}}$ & $38.29 \pm 0.18^{\mathrm{e}}$ & $0.086 \pm 0.01^{\mathrm{c}}$ & $0.140 \pm 0.06^{\mathrm{c}}$ & $0.54 \pm 0.02^{\mathrm{b}}$ \\
\hline Squeeze washed with palmoil & $232.44 \pm 0.02^{\mathrm{c}}$ & $48.10 \pm 0.02^{\mathrm{c}}$ & $0.078 \pm 0.02^{b}$ & $0.151 \pm 0.02^{b}$ & $0.56 \pm 0.03^{b}$ \\
\hline
\end{tabular}

Values are means and standard deviations of three replicates; means with the same superscript are not significantly different $(\mathrm{p}<0.05)$

\section{Conclusion}

Nutrient retention and losses in the bitter leaf samples varied from 23 to $61 \%$, and 27.3 to $80.5 \%$ respectively. The sample squeeze-washed with palm oil exhibited a high (55$100 \%$ ) nutrient uptake (moisture, protein, fibre, vitamin A e.t.c) than the remaining samples (38 to $65 \%$ ), although the range of nutrient losses remained the same $(27.3$ to $80.5 \%)$ in all sample. By implication, losses of nutrients depended on changes induced by the intensity of the squeeze-washing process to disintegrate the vegetable structurally rather than composition of each vegetable samples. Furthermore, nutrient gain of some of the samples is dependent on the compositions of the material of squeeze-washing (palm oil) and retention of its cellular structure. It is recommended that palm oil be used in the squeeze-washing of bitter leaf for better nutrient retention.

\section{References}

[1] A.O.A.C. (2005) Official methods of Analysis of Association of Analytical Chemists. Washinghton D.C.

[2] Adeboye, A.S. and Babajide, I.M. (2007) Effects of processing methods on anti-nutrients in selected leafy vegetables. Nigerian Food Journal 25(2): 77-87.
[3] Adepoju, O.L.T., Onasanya, L.O. and Udoh, C.H. (2006) Comparative studies of nutrient composition of cocoyam (Colocassia esculanta) leaf with some green leafy vegetables. Nig. J. Nutr. Sci., 27 (1): 22-26.

[4] Aina, J.O. U.O, E.E. (1990) Bitter Leaf (vernonia amygdalina): A potential tropical hop substitute.. Discovery and Innovation 2:63-66.

[5] Ajayi, I.A., Oderinde R.A, Kalogbola, D.O and Ukponi J.U (2006). Oil of underutilized legumes from Nigeria. Food chemistry 99(1): 115-120.

[6] Ajebesome, P.E and Aina, J.O. (2004). Potential African substitutes for hops in tropical beer brewing. African Journal of Food Technology 9:13-16

[7] Akubugwo, , I.E., Obasi, N.A., Chinyere, G.C. and Ugbofu, A.E. (2007). Nutritional and chemical value of Amarathus hybridus $L$. leave from Afikpo, Nigeria. African Journal of Biotechnology 6(24):2833-2839.

[8] Akubugwo, I.E., Obasi, N.A., chinyere, C.O and Ugbofu, A.E (2008)Mineral and photochemical contents in leaves of Amaranthus hybridus L. and Solanum nigruumn L. subjected to different processing methods. African Journal of Biochemistry Research 2(3):40-44.

[9] Aletor, M.V. and Adeogun, O.A. (1995). Nutrient and antinutrient compostion of some tropical leafy vegetable. Food chemistry 54(4): 375-379. 
[10] Atangwho, I.J., Ebong, P.E, Eyong, E.U., Williams, I.O, Eteng, M.U. and Egbung, G.E. (2009). Comparative chemical composition of leaves of some anti-diabetic medicinal plants: Azadirachta indica, Vernonia amygdalina and Gongronema Latifolium. African Journal of Biotechnology 8(18):4685-4689.

[11] Chima, C.E. and Igyor, M.A. (2007). Micronutrients and antinutritional contents of selected tropical vegetable grown in south-Eastern Nigeria. Nigerian Food Journal. 25(1):111-117.

[12] Ejoh, A.A., Djuikwo, V.N., Gouado, I. and Mbofung, C.M. (2007a). Nutritional components of some non-conventional leafy vegetables consumed in Cameroon. Pakistan Journal of Nutrition 6(6):712-717.

[13] Ejoh, A.R., Tchouanguep, M.F. and Fokou, E. (1996). Nutrient compostion of the leaves and flower of Colocassia esculenta and the fruits of Solanum melongena. Plant Food for Human Nutr. 49:107-112.

[14] Enwere, N.J. (1998). Foods of Plant Origin. Afro Orbis Publication Ltd, Nsukka pp.160-166.

[15] Eunok, C., Rongmin, h. and David, B.M (2005). Chemical reaction and stability of Riboflavin in foods. Journal of food Science70 (1): R29-R36.

[16] Gupta, S., Lakshmi, A.J., Majunah, M. N and. Prakash, J. (2005). Analysis of nutrient and antinutrient contents of underutilized green leafy vegetables LWT. Food Science and Technology 38:339-345.

[17] Hildreth, E.M. (1971) Elementary Science of Food. The trinity Press Worcester, London Pp35-62.

[18] Ifon, E.T and Bassir, O. (1980). The nutritive value of some Nigeria Leafy Vegetable Part 2: the distribution of protein, carbohydrates (including Ethanol, Soluble simple Sugars), Crude fat, Fibre and Ash. Food Chemistry 5:231-235.

[19] Ifon, E.T and Bassir, O. (1989). The nutritive value of some Nigeria leafy Green Vegetable Part 1: vitamin and Mineral contents. Food chemistry 4:263-267.

[20] Igile, G.O., Oleszyek, W., Burda, S. and Jurzysta,N. (1995). Nutritional assessment of Veronomia Amygdalina leaves in growing mice. Journal of Agriculture and Food Chemistry 43:2162-2166.

[21] Ihekoronye, A.I and Ngoddy, P.O (1985) Tropical Fruits and Vegetables in: Intergrated Food Science and Technology for the Tropics, Macmillian pub.Ltd, London p293-311.

[22] International Gaithersburg, MD. USA: 134-143.

[23] Julie, B. (2003). The importance of Vitamins and their role in our body. Ezine Articles pp.1-5.

[24] Kelsay, J.C. and Prather, E. (1985). Mineral balance of Human subject consuming Spinach in low fiber diet and in a diet containing fruits and vegetables. Amer J. Clin. Nutr. 38:12-19.

[25] Kola. A. (1999). Analysis of the nutritive element of some Nigerian leafy vegetables. Proceedings of $3^{\text {rd }}$ annual Conference of Nigerian institute of Food Science and Technology held in Abuja p.158.

[26] Lund, G.O and Smoot,J.M (1982). Dietary fiber content of some tropical fruits and vegetables. J. Agric Food chem...30:1123-1127.
[27] Lassen, A., Kall, M., Hansen, K. and ovesen, L. (2002). A comparison of the retention of vitamins B1, B2 and B6 and cooking yield in pork loin with conventional and enhanced meal-service systems. European Food Research Technology 215:194-199.

[28] Latham, M.G. (1997). Human nutrition in developing world. FAO Rome Food and Nutrition Series. P.315

[29] Latunde-Dada, G.O (1990). Effects of processing on Iron level in and bioavailability from Nigerian vegetables. Journal of Food Science and Agriculture 5:355-361.

[30] Lean M.N., (2006). Vitamins and other bioactive food constituents in: Food Science, Nutrition and Health $\left(7^{\text {th }}\right.$ edition). Edward Hodder Ltd, London pp198-216.

[31] Lewu, M.N., Adebola, P.O and Afolayan, A.J. (2009). Effects of cooking on the proximate composition of the leaves of some accession of Colocassia esculenta (L) Shoot in Kwazulu- Natal Province of South African. African journal of biotechnology 8(8):1619-1622.

[32] Lyimodo, M., Nyagwegwe, S.N and Ap Mnkem (1991) Investigations of Traditional Food for Human Nutrition 41; 53-57.

[33] Mayhew,S. and Penny, A. (1998). Tropical and Subtropical Foods Macmillian Publishers, London, p.107

[34] Morah, G.N. and Obiegbuna, J.E. (2002). The effect of different pre-washing and washing treatment on some chemical and sensory properties of bitter leaf vegetable. Nigerian Food Journal 20:52-57.

[35] Nkafamiya, I.I., Manji, A.J., Modibbo, U.U. and umaru, H.A. (2006). Biochemical evaluation of Casspourea congoensis (Tunti) and Nudea Latifolia (UZZIZA) FRUITS. African Journal of Biotechnology 6(19): 2461-2463.

[36] Nkafamiya, I.I., Oseameahon., S.A. Modibbo, u.U. and Haggai, D. (2010). Vitamins and effect of blanching on nutritional values of non-conventional leafy vegetables. African Journal of Food Science 4(6): 335-341.

[37] Okafor, J. C. (1983). Horticulturally promising indigenous wild plant species of the Nigerian forest zone Acta. Nort. 123:165-176.

[38] Okafor, J.C. (1979). Edible indigenous woody plants in the rural ecosystem (D.U.U. Okali, ed). Proceeding of M.A.B. Workshop on the Nigerian Rainforest Ecosytem. University of Ibadan, Nigeria.

[39] Okafor, J.C. (1995). Conservation and use of traditional vegetables from woody forest species in South-Eastern Nigeria in: Proceedings of the IPGRI Workshop on Genetic Resources of Traditional vegetables in African, Nairobi.

[40] Okwu, D.E. (2004). The phytochemical and vitamin content of indigenous species of South Eastern Nigeria leaves. Journal of Sustained Agriculture and Environment 6:30-34.

[41] Okwu, D.E. Ndu, C.U. (2006). Evaluation of the Phytonutrients, Minerals and vitamin content of some varieties of Yam (Doscorea spp). International Journal of Molecular Medicine and Advanced Sciences 2(2):199-203.

[42] Ruttledge, P. (1991). Preparation Procedures in: Arty. V.D. and Dennis, C. (eds) Vegetables Processing in U.K. Blackie, Glasgow p.68. 
110 Agomuo Jude Kelechi et al:: Effect of Traditional Methods of De-bittering on the Proximate and Vitamin Contents of Fresh and Squeezed-Washed Bitter Leaf

[43] Said,H.M. and Mohammed, Z.M. (2006) "Intestinal Absorption of Water-soluble Vitamins: an update". Curr. Opin. Gastroenteral 22(2): 140-146.

[44] Saidu, A.N. and Jideobi, N.G. (2009. The proximate and elemental analysis of some leafy vegetables grown in Minna and Environs. Journal of Applied Science Environment and Management 13(4):21-22.
[45] Uwaegbute, A.C. (1989). Vegetable Nutrition and utilization. In: Mba, B.E. and Nnanyelugo D.C. (eds) Food Crops Production, Utilization and nutrition. Dotam Publishers Ltd, Ibadan, Nigeria; pp.145-153. 